\title{
IMPACT OF CENTRAL VENOUS PRESSURE AND DIURESIS ON RENAL GRAFT FUNCTION
}

\author{
Semir IMAMOVIĆ ${ }^{1}$ \\ Farid LJUCA ${ }^{2}$ \\ Dešo MEŠIĆ ${ }^{3}$ \\ Šefik HASUKIĆ ${ }^{3}$ \\ Safet OMEROVIĆ ${ }^{4}$ \\ Mustafa BAZARDŽANOVIĆ ${ }^{4}$ \\ Fatima ILJAZAGIĆ-HALILOVIĆ ${ }^{1}$ \\ ${ }^{1}$ Department of Anesthesiology \\ and Reanimatology, \\ University Clinical Centre Tuzla, Tuzla \\ ${ }^{2}$ Department of Physiology, \\ Medical faculty University in Tuzla, Tuzla \\ ${ }^{3}$ Surgical Department, \\ University Clinical Centre Tuzla, Tuzla \\ ${ }^{4}$ Regional Medical Centre \\ "Safet Mujić", Mostar
}

Bosnia and Herzegovina

Received:14.09.2008.

Accepted: 22.01.2009

Corespondence to:

Semir Imamović, $M D$, PhD

Department for Anesthesiology and Reanimation

University Clinical Centre Tuzla

Trnovac bb, 75000 Tuzla

Bosnia and Herzegovina

e-mail:semirim2000@yahoo.com

\begin{abstract}
Introduction: Renal graft function in the immediate posttransplant period is directly associated with patients hemodynamic condition during graft revascularization and early postoperative period. Our aim was to evaluate correlation between average daily value of central venous pressure (CVP) and renal perfusion, in first seven posttransplant days.

Patients and methods: We recruited 74 patients, who underwent renal transplantation. We evaluated the influence of CVP and $24 \mathrm{~h}$ urine output on renal graft function. In order to assess the renal graft function, following parameters were evaluated: glomerular filtration rate (GFR), creatinine clearance, 24-hour urine output, and from the serum levels of $\mathrm{K}^{+}, \mathrm{Na}^{++}$, urea and creatinine.

Results: Statistically significant positive correlation between mean values of CVP and $24 \mathrm{~h}$ urine output was found on the first $(\mathrm{r}=0.5422 ; \mathrm{p}=0.0001)$ but not on the third postoperative day $(r=0.1116 ; p=0.344)$. Statistically significant inverse correlation between mean values of creatinine and diuresis was found on the first $(\mathrm{r}=-0.2824 ; \mathrm{p}=0.015)$ and third $(\mathrm{r}=-0.2976 ; \mathrm{p}=0.01)$ postoperative day but on the seventh postoperative day a positive statistically significant correlation between these parameters was registered $(\mathrm{r}=0.4114 ; \mathrm{p}=0.0001)$. There is a statistically significant difference between GFR and urine output on the first ( $r=0.2771 ; \mathrm{p}=$ 0.017 ) and seventh day ( $r=0.4114 ; \mathrm{p}=0.0001)$. We have not found any significant correlation between mean values of creatinine clearance and diuresis on the first posttransplant day $(r=0.1760 ; p=0.134)$, but when same parameters were examined on the seventh day a positive statistical significance was found $(r=0.4248$; $\mathrm{p}=0.0001$ ).

Conclusion: Renal graft survival in early postoperative period is largely influenced by recipient hemodynamic condition. This study proved that 24-hour urine output directly depended on CVP level; it also proved existence of statistically significant correlation between mean values of diuresis, creatinine clearance, GFR and serum creatinine.
\end{abstract}

Key words: renal graft, central venous pressure, 24-hour urine output

\section{INTRODUCTION}

Posttransplant renal graft function is not exclusively determined by pretransplant donor and graft characteristics. In the normal kidney, vasodilatation of afferent arterioles ensures stabile renal blood flow over a range of perfusion pressures. This autoregulatory mechanism is absent in experimental models of ischemic acute renal failure, thus making ischemic kidney vulnerable to minor changes in hemodynamic status. ${ }^{1}$
A transplanted kidney undergoes several physiological and immunological insults. In initial period of reperfusion there is free radical mediated damage to renal microvasculature, which initiates a cascade of molecular and cellular interactions, involving marginating of leukocytes and secretion of vasoactive molecules both by platelets ant the endothelium. ${ }^{2}$ Postoperative hemodynamic evaluation is crucial for several reasons: for routine postsurgical management; to optimize graft function; to asses significance of urine output or lack 


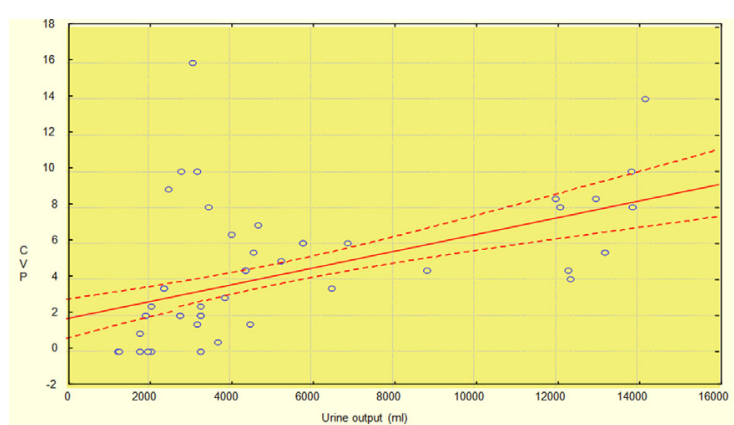

Figure 1. Correlation between mean values of $24 \mathrm{~h}$ urine output and central venous pressure on the first postoperative day

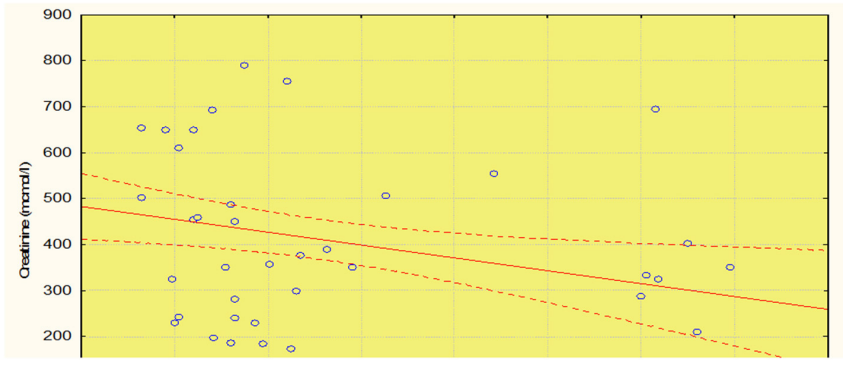

Figure 2. Correlation between mean values of $24 \mathrm{~h}$ urine output and central venous pressure on the third postoperative day

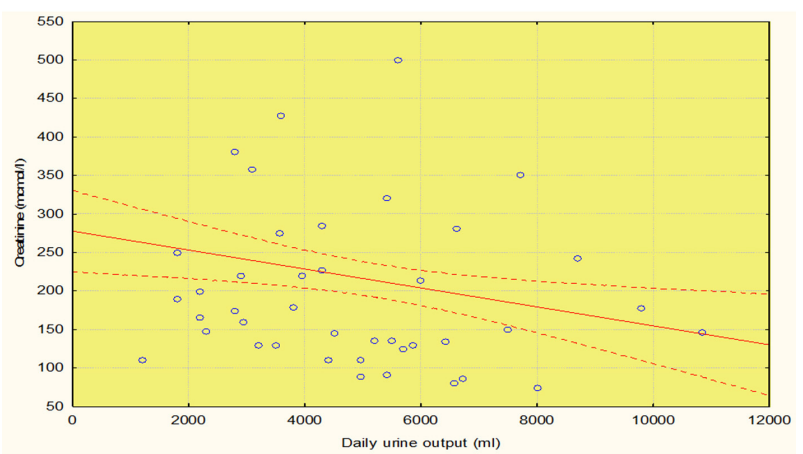

Figure 4. Correlation between mean values of creatinine and $24 \mathrm{~h}$ urine output on the third postoperative day

there of; and to undertake prompt therapeutic intervention. ${ }^{3}$ Aggressive hydration maintains high minute volume and adequate renal blood flow. Increased CVP causes atrial stretching which stimulates secretion of atrial natiriuretic peptide (ANP) by heart muscle cells. ANP increases the glomerular filtration rate (GFR), resulting in greater excretion of sodium and water, decreases sodium reapsorption, inhibits renin secretion and reduces aldosteron secretion by the adrenal cortex. Increased concentration of ANP prevents development of ischemia and action of nephrotoxic substances. ${ }^{4}$ The recipient's hemodynamic condition during graft revascularization and early postoperative course has a major influence on graft survival and development of delayed graft function. ${ }^{5}$

Adequate perfusion of transplanted kidney can be accomplished by expansion of intravascular volume of the recipient. Our aim was to evaluate correlation be-

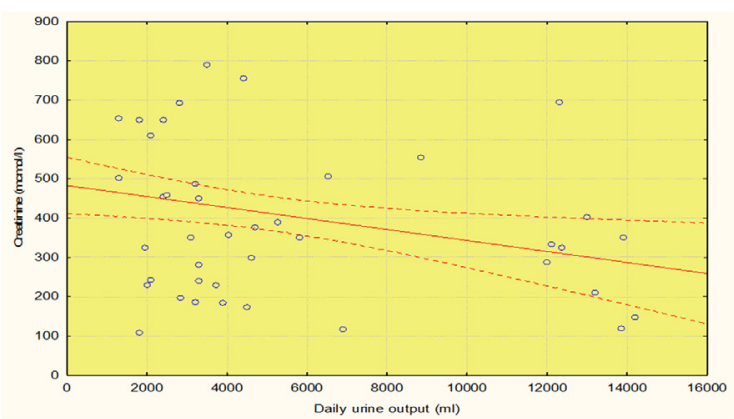

Figure 3. Correlation between mean values of creatinine and $24 \mathrm{~h}$ urine output on the first postoperative day

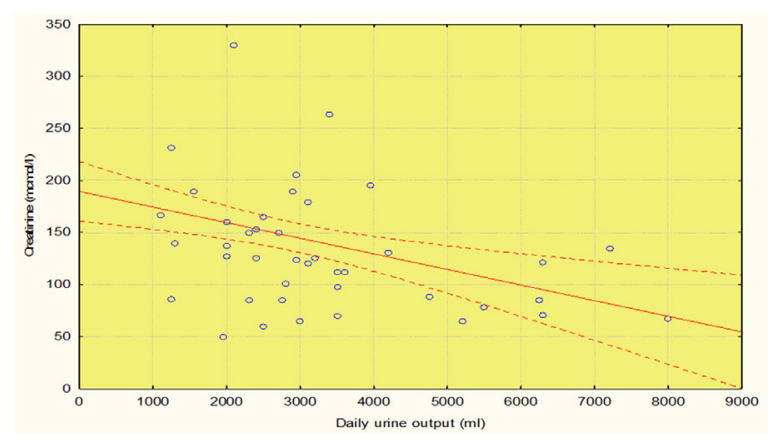

Figure 5. Correlation between mean values of creatinine and 24 h urine output on the seventh postoperative day

tween average daily value of CVP and renal perfusion, in first seven posttransplant days.

\section{PATIENTS AND METHODS}

This is an observational cohort study that recruited 74 patients who underwent kidney transplantation. Seventy patients received living donor kidney transplant and four patient received kidney transplant from a deceased donor. All patients were assessed as ASA IV (American Society of Anesthesiologists) physical status. Balanced anesthesia was used in all transplant patients. In order to assess renal graft function, following parameters were evaluated: GFR $(\mathrm{ml} / \mathrm{min})$ creatinine clearance ( $\mathrm{ml} / \mathrm{min}), 24 \mathrm{~h}$ urine output, and from the serum levels of $\mathrm{K}^{+}$, $\mathrm{Na}^{++}$, urea (mmol/L), creatinine $(\mu \mathrm{mol} / \mathrm{L})$. All parameters were assessed daily in first seven post transplant days. CVP was measured 


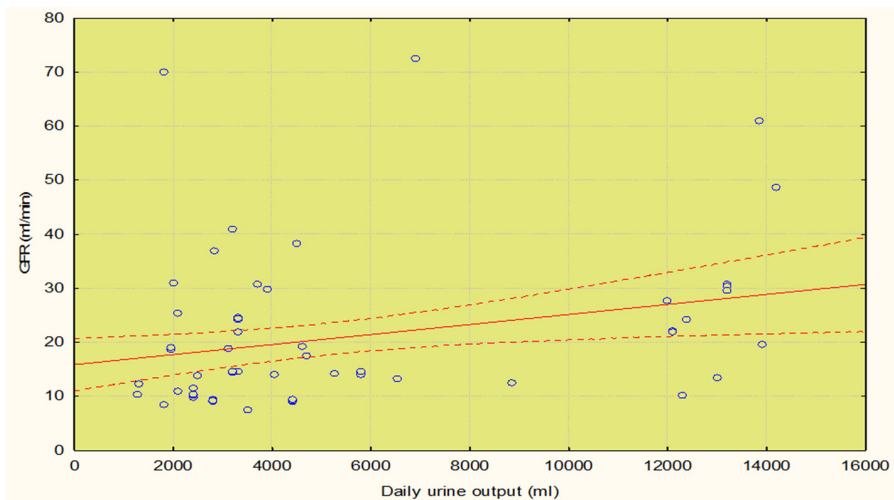

Figure 6. Correlation between mean values of GFR and $24 \mathrm{~h}$ urine output on the first postoperative day

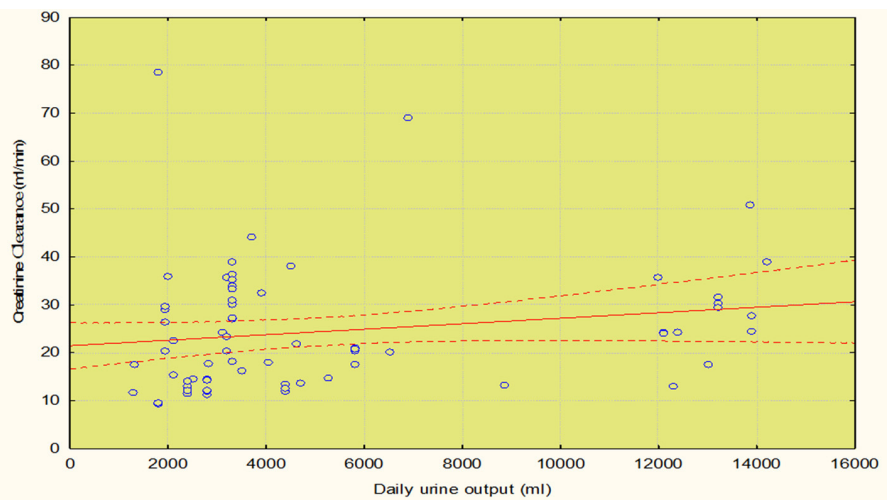

Figure 8. Correlation between mean values of creatinine clearance and $24 \mathrm{~h}$ urine output on the first postoperative day

every four hours; in our research we used average daily values. Glomerular filtration rate was calculated using following formula:

GFR $=270 \times \mathrm{Cr}^{-1.007} \times$ Age $^{-0.18} \times$ Urea $^{-0.169} \times 0.755$ (female) ${ }^{6}$

\section{Statistical analysis}

The statistical analysis was performed using Pearson's test, p-value of less than 0.05 was considered statistically significant.

\section{RESULTS}

The study was conducted in University Clinical Centre Tuzla and included 74 patients with mean age of $32.9 \pm 9.7$ years and with 51 males and 23 females. Mean donor age was $49.2 \pm 12.2$ years with 26 donors older then 55 years. All patients received cyclosporine postoperatively; other than with cyclosporine, 34 patients were treated with mycophenolate mofetil, and the rest of them with azathioprine. As additional immunosuppressive therapy 33 patients received basiliximab.

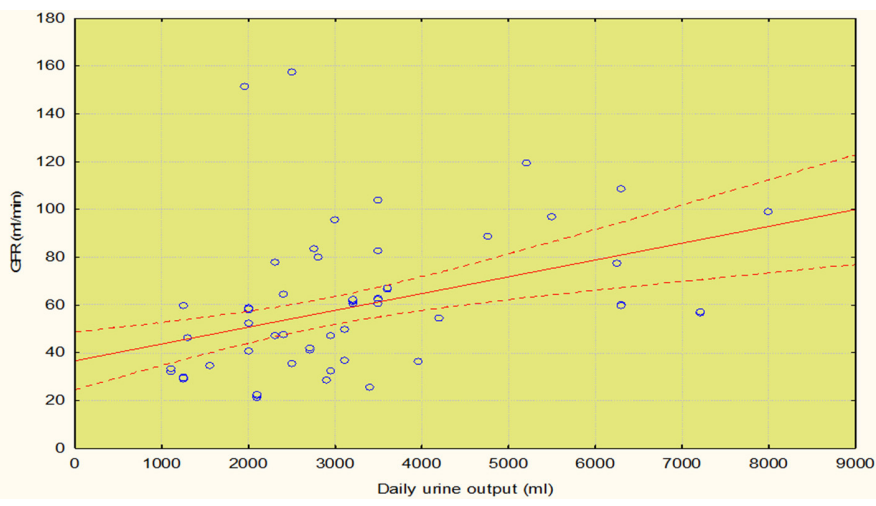

Figure 7. Correlation between mean values of GFR and $24 \mathrm{~h}$ urine output on the seventh postoperative day

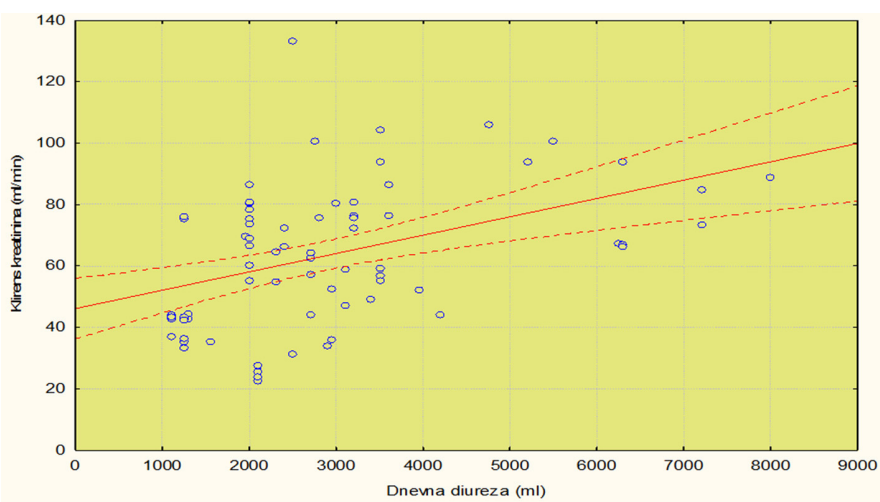

Figure 9. Correlation between mean values of creatinine clearance and $24 \mathrm{~h}$ urine output on the seventh postoperative day

\section{Correlation between mean values of 24-hours urine output and CVP}

Average values of 24-hours urine output are directly related to CVP values. Statistically significant positive correlation between mean values of CVP and urine output was found on the first postoperative day $(\mathrm{r}=0.5422 ; \mathrm{p}=0.0001)$ (Figure 1). Above mentioned parameters did not differ significantly on the third post operative day $(r=0.1116 ; p=0.344)$, (Figure 2$)$.

\section{Correlation between mean values of creatinine and 24-hours urine output}

Serum creatinine concentration directly depends on 24-hours urine output. On the first postoperative day statistically negative correlation was found between these parameters $(\mathrm{r}=-0.2824 ; \mathrm{p}=0.015)$, (Figure 3).

Inverse correlation between mean values of creatinine concentrations and 24-hours urine output was pronounced on the third postoperative day ( $\mathrm{r}=$ 0.2976; $p=0.01$ ), (Figure 4).

Although creatinine values tends to lower daily, on the seventh posttransplant day inverse statistical significance was highest ( $r=-0.3757 ; p=0.001)$, (Figure 5). 


\section{Correlation between mean values of GFR and 24-hours urine output}

Even on the first posttransplant day there was a positive statistical significance when mean values of GFR and 24-hours urine output were observed $(r=0.2771$; $\mathrm{p}=0.017$ ), (Figure 6).

On the seventh postoperative day values of GFR are still rising and positive correlation between these parameters is the highest $(r=0.4114 ; p=0.0001)$, (Figure 7).

\section{Correlation between mean values of creatinine clearance and 24-hours urine output}

Correlation between mean values of creatinine clearance and 24-hours urine output showed no statistical significance on the first posttransplant day $(r=0.1760$; $\mathrm{p}=0.134$ ), (Figure 8).

Statistically significant positive correlation between mean values of creatinine clearance and 24-hours urine output was the highest on the seventh posttransplant day ( $r=0.4248 ; p=0.0001)$, (Figure 9).

\section{DISCUSSION}

Kidney graft outcome is influenced by multiple parameters. Besides surgical and immunological causes, graft rejection or its diminished function can also be impacted by other risk factors, such as: donor age, recipient hypertension, modes of immunosuppressive treatment, hemodynamic stability and hyperlipidemia. These factors represent a major component in graft outcome particularly in early posttransplant period and can considerably worsen graft survival prognosis. ${ }^{7}$ Organ transplant induces several physiological changes in recipient organism, which has been exposed to chronic dialysis during anephritic phase and usually suffers from fluid and electrolytes disorders.

Ferris et al. recorded low CVP values during early postoperative period, that persisted despite aggressive fluid resuscitation, even when fluid input exceeded losses up to 4 liters. ${ }^{8}$ The maximum drop in CVP occurred between operating room and intensive care unit (ICU). Factors such as prompt redistribution of fluids and possibility that patients with end stage renal disease may have a different post anesthetic response might be responsible for this phenomenon. ${ }^{9}$ The average CVP drop was observed in the recipients of both deceased and living related renal grafts one to two hours after arriving to ICU, low CVP persisted for next 4 to 8 hours, indicating that drop in CVP occurs with reperfusion of the kidney. The best studied response to reperfusion is generation of oxygen derived free radicals. ${ }^{10}$ Tissue damage with consequent increase in vascular permeability, activation of leucocytes and al- terations in vascular tone are known to result from the free radicals; several arachidonic acid metabolites are also released. Either of these events could have contributed CVP drop. ${ }^{8,9}$

Another factor contributing to low post operative values of CVP could be increased level of nitric oxide (NO) following kidney transplantation, due to excretion of an inhibitor of nitric oxide synthase by transplanted kidney. ${ }^{10} \mathrm{~A}$ value of serum creatinine is the earliest measurable parameter in assessment of renal graft metabolic function. Zukowski et al. analyzed the age, gender, cause of death, mean arterial pressure, CVP, cardiac output, systemic vascular resistance and other hemodynamic parameters in early postoperative period and in first six posttransplant months. ${ }^{11}$

We found no statistically significant increase in creatinine clearance in correlation with 24 hour urine output on the first postoperative day. On the third postoperative day creatinine clearance was significantly higher in patients with higher 24 hour urine output; this significance is even higher on the seventh posttransplant day. Recent studies have observed clinical usefulness of correlation between central and peripheral venous pressure (PVP) ant its influence on renal graft function. Hadimioglu et. al. analyzed influence of CVP and PVP on renal graft function. They found positive correlation between preoperative and postoperative values of CVP and PVP with renal graft function. ${ }^{12}$ Our findings confirm these results.

Aggressive intraoperative intravascular volume expansion is recommended, aiming to maximize renal perfusion and decrease risk of delayed graft function (fluid input up to $30 \mathrm{ml} / \mathrm{kg} / \mathrm{h}, \mathrm{CVP}>15 \mathrm{~mm} \mathrm{Hg}$ ). In patients with latent cardiac disease or diminished myocardial function risk of cardiac overload or acute respiratory insufficiency is increased. De Gasperi et al. found satisfactory renal graft recovery in $94 \%$ recipients. However, in remaining $6 \%$ outcome was poor, despite intensive hydratation. ${ }^{13}$ Improving recipient hemodynamics by expansion of the intravascular volume does not guarantee successfulness of kidney transplantation.

\section{CONCLUSION}

Our research proved significant correlation between average values of 24 urine output, GFR, creatinine clearance and mean values of CVP, as well as inverse correlation between mean values of serum creatinine and CVP in first seven posttransplant days. Monitoring and maintenance of adequate hemodynamic parameters (CVP, arterial tension, cardiac output) as well as immunosuppressive regimen, during surgery and in early postoperative course are crucial in renal graft survival. Expansion of intravascular volume is vital in preserving hemodynamic stability, tissue oxygenation and 
organ function. Crystalloids infusions are first choice in correction of fluid and electrolytes disorders. In severe hypovolemia and especially in cases of disturbed cell membrane permeability, adequate tissue perfusion can be obtained by using colloid solutions. CVP ranging from 10 to $15 \mathrm{~cm} \mathrm{H}_{2} \mathrm{O}$, insures optimal intravascular volume and lowers risk of acute tubular necrosis thereby solving hypovolemia related problems. Implementation of aggressive fluid resuscitation protocol prevents delayed graft function and acute graft rejection, and increases successfulness of kidney transplantation.

\section{REFERENCES}

1. M. G. J. Snoeijs, B. Wiermans, M. H. Christijaans, J. P. van Hoof et al: Recipient Hemodynamics during Non-HeartBeating Donor Kidney Transplantation Are Major Predictors of Primary Nonfuction. American Journal of Transplantation 2007; 7: 1158-66.

2. Koo DD, Welsh KI, Roake JA et al: Ischemia/reperfusion injury in human kidney transplantation: an immunohistochemical analysis of changes after reperfusion. Am J Pathol, 1998; 153(2): 557-6.

3. Danovitch, Gabriel M. Handbook of Kidney Transplantation, 4th edition. Lippincott Williams \& Wilkins; 2005; 213-33.

4. Demetriou D, Wenter C, Watschinger B: Vasoactive substances in renal transplantation. Curr Opin Urol, 2000; 10(2): 63-9.

5. Collins GM, Dubernard JM, Land W, Persijn CG Procurement. Preservation and Allocation of Vascularized Organs. Kluwer Academic Publishers. 1997: 567-600.
6. Levey AS, Bosch JP, Lewis JB Greene T, Rogers N, Roth D. A more accurate method to estimate glomerular filtration rate from serum creatinine: a new prediction equation. Modification of Diet in Renal Disease Study Group. Ann Intern Med. Mar. 1999; 130(6): 461-70.

7. Hooff JP, Gelens M, Boots JM, van Duijnhoven EM, Dackus J, Christiaans MH. Preservation of renal function and cardiovascular risk factors. Transplant Proc 2006; 38(7): 198791.

8. Ferris RL, Kittur DS, Wilasrusmee C, Shah G, Krause E, Ratner L. Early hemodynamic changes after renal transplantation: determinants of low central venous pressure in the recipients and correlation with acute renal dysfunction. Med Sci Monit 2003; 9(2): CR61-6.

9. Weinberg JM: The cell biology of ischemic renal injury. Kidney International, 1991; 39:476.

10. Kang ES, Miles DE, Tevlin MT et al: Reversible sequestration of nitric oxide by hemoglobin during hemodyalisis in end stage renal disease. Am J Med Sci 2001; 321(2): 113-23.

11. Zukowski M, Bohatyrewicz R, Krawczyk AA. Influence of selected factors on occurrence of delayed kidney graft function: a multivariate analysis. Transplant Proc 2007; 39(9): 2704-6.

12. Hadimioglu N, Ertug Z, Yegin A, Sanli S, Gurkan A, Demirbas $A$. Correlation of peripheral venous pressure and central venous pressure in kidney recipients. Transplant Proc 2006; 38(2): 440-2.

13. De Gasperi A, Narcisi S, Mazza E, Bettinelli L, Pavani M, Perrone L, Grugni C, Corti A. Perioperative fluid management in kidney transplantation: is volume overload still mandatory for graft function? Transplant Proc 2006; 38(3): 807-9. 